\title{
Supporting people building their own response to the consequences of a nuclear accident: complexity management, trust and the Aarhus Convention
}

\author{
G. Heriard-Dubreuil and S. Baudé \\ MUTADIS, Paris, France.
}

\begin{abstract}
PREPARE work package on "Information and participation of the public" has investigated the conditions and means for pertinent, reliable and trustworthy information to be made available to the public in due time and according to its needs in the course of nuclear emergency and post-emergency contexts. These works addressed three different issues: experts-to-expert interactions in an emergency and post-emergency situation, information and participation of local populations affected by a post-accident situation, and communication with traditional and social media in nuclear or radiological emergencies. These three directions of work shared common perspectives and hypotheses. The first one was the specific perspective on information and participation of the public of the Aarhus Convention (1998), according to which information and participation of he public is required in order for affected people to take action in order "to take measures to prevent or mitigate harm arising from the threat". The second common conceptual basis is the acknowledgement of the complexity of a post-accident situation and the non-linear character of the system of information and action in such situations, which integrated a wide diversity of actors and of information providers. Finally, following Niklas Luhman's works, trust is addressed as a tool to address complexity.
\end{abstract}

Keywords: European project PREPARE / information / participation / local populations / Fukushima / Chernobyl / Aarhus Convention / long-lasting contamination

PREPARE included a specific work package addressing "Information and participation of the public". This research has investigated the conditions and means for pertinent, reliable and trustworthy information to be made available to the public in due time and according to its needs in the course of nuclear emergency and post-emergency contexts, according to the principle of the Aarhus Convention on information, participation of the public and access to justice in environmental matters. PREPARE addressed this issue through three different issues:

- Experts-to-expert interactions in an emergency and postemergency situation.

- Information and participation of local populations affected by a post-accident situation.

- Communication with traditional and social media in nuclear or radiological emergencies.

This article presents the common perspective and research hypotheses that underlie these three directions of work: the Aarhus Convention on access to information, public participation in decision-making and access to justice in environmental issues, complexity of post-accident issues and trust as a tool to address complexity.

\section{Information and participation of the public: the perspective of the Aarhus Convention}

Information and participation of the public, in the perspective of supporting the capacity of affected actors to protect themselves, is notably a requirement of the Aarhus Convention on Access to Information, Public Participation in Decision-making and Access to Justice in Environmental Matters. This Convention, that addresses decision-making in environmental matters in general, also specifically addresses crisis situations, stating (Article 5.1.c) that "In the event of any imminent threat to human health or the environment, whether caused by human activities or due to natural causes, all information which could enable the public to take measures to prevent or mitigate harm arising from the threat and is held by a public authority is disseminated immediately and without delay to members of the public who may be affected."

In this perspective, information and participation of the public is understood as:

- the understanding (by the public) of the evolution of the accident (and potential risks) along its management; 
- the capacity of the population and communities to prevent or mitigate harm arising from the threat, individually and collectively.

\section{Complexity in post-accident issues}

Emergency and post-accident situations are of a complex nature insofar as they involve a large number of actors and a large number of intrinsically interlinked dimensions and issues (heath, environmental, economic, social, cultural, ethical,... dimensions). In such situations, people and organisations have to face this complexity in a context in which the usual social and institutional routines are often particularly challenged and destabilised.

In the context of modern democratic political regimes and information and communication societies, we can assume that the information flows and systems of action are also of a complex nature, opposed to a vision of information processes as a linear chain composed of an emitter, a media and a receiver, and to top-down conceptions of post-emergency management and recovery.

The system of information and action is thus assumed to integrate a wide variety of information providers and relays, and a large number of actors engaging into action, beyond organisations with an institutional mandate of emergency and post-emergency management and public authorities.

\section{Trust as a resource to address complexity}

The works of Niklas Luhmann on trust identify trust as a means for individuals to address complexity. This understanding of trust differs from an instrumental vision of trust in which an actor seeks to gain trust from others. In situations like postaccident situations, in which the usual mechanisms of trust are broken, it is necessary for people to find ways to build new mechanisms of trust, which are based on plurality (of expertise, of information sources, of access to measurements, ...).

A hypothesis made in PREPARE works on information and participation of the public is that in a post-accident situation, plurality of actors, of information flows, of experts, is a resource to address complexity and to rebuild new systems of trust through new emerging paths and procedures. The question here is not how to reach a consensus between experts of how to have an information provider that would be trusted by all, but rather how plurality of experts and of information flows can contribute to the emergence of a situation where people can make their own opinion in a robust way by looking at the outcomes of interactions between different types of experts.

Acknowledgement. The research leading to these results has received funding from the European Atomic Energy Community Seventh Framework Programme FP7/2012-2013 under grant agreement 323287.

Cite this article as: G. Heriard-Dubreuil, S. Baudé. Supporting people building their own response to the consequences of a nuclear accident: complexity management, trust and the Aarhus Convention. Radioprotection 51(HS2), S153-S154 (2016). 